\title{
Alteration Development of the Simulated HLW Glass at High Temperature in Beishan Underground Water
}

\author{
Zhentao Zhang, Xueying Gan, Lei Wang, and Haiqing Xing \\ Department of Radiochemistry, China Institute of Atomic Energy, Beijing 102413, China \\ Correspondence should be addressed to Zhentao Zhang, zhangzhentaociae@126.com
}

Received 3 April 2011; Revised 19 December 2011; Accepted 19 December 2011

Academic Editor: Michael I. Ojovan

Copyright ( $) 2012$ Zhentao Zhang et al. This is an open access article distributed under the Creative Commons Attribution License, which permits unrestricted use, distribution, and reproduction in any medium, provided the original work is properly cited.

\begin{abstract}
The simulated HLW glass was found to be altered in Beishan underground water at high temperature in two different stages starting with slow leaching of the immobilized elements for a period followed by a sharp degradation of the glass matrix. Immersed at $150^{\circ} \mathrm{C}$ in Beishan underground water with glass-surface-area-to-solution-volume ratio of $6000 \mathrm{~m}^{-1}$, the glass was alterated rapidly with the sharp release of B, Na, Li, Cs, and Mo from the cold HLW glass after a stable period of 180 days. The glass was degraded up to $73.6 \%$ for the immersion period of 730 days resulting in the release of Mo and Cs up to $73.6 \%$ and $2.7 \%$ from the glass, respectively. With the alteration underway, new minerals were identified to be zeolite $\mathrm{P}$, mordenite, nontronite, dickite, okonite, quartz, saponite, and tincalconite. However, at low temperature of $90^{\circ} \mathrm{C}$, the glass was very stable with limited leaching of Na, B, and Li.
\end{abstract}

\section{Introduction}

The reprise of alteration of HLW glass in aqueous media is the inherent properties of glass and it occurs after the glass alteration reached a stagnant period followed by the rapid realteration of glass resulting in the sharp release of the radionuclide immobilized in the glass matrix. Therefore, the reprise of alteration of HLW impacts significantly the performance of the geological repository and it is necessary to study the reprise of alteration of HLW.

The reprise of alteration of R7T7 glass could be influenced by $\mathrm{pH}$, temperature, and S/V [1]. The R7T7 glass was found to have the reprise of alteration after immersed for 250 days when the $\mathrm{pH}$ of the aqueous media was more than 11 . When the S/V exceeds $100 \mathrm{~cm}^{-1}$, the reprise of alteration of occurred after the R7T7 glass was immersed for 1 year. If the temperature of the aqueous media is higher than $150^{\circ} \mathrm{C}$, the reprise of alteration will happen. The Savannah HLW glass SRL131A was observed to have the reprise of alteration after being immersed in the underground water from the well J13 for more than 6 years while the reprise of alteration of SRL200S glass occurred after immersion of 3 years [2-5]. The Pamela SAN60 glass had the reprise of alteration after 2 years of immersion [6, 7]. It was found that the high aluminum content in the glass was the main reason to cause the reprise of alteration [8].

In order to prevent the reprise of alteration of HLW glass, it is necessary to study the reprise of alteration of China's HLW glass and to study the conditions to cause the reprise of alteration.

\section{Experimental}

2.1. The Fabrication of the Simulated HLW Glass. The simulated HLW glass was fabricated by fusion of the mixture of nitrate, carbonate, and oxides to $1150^{\circ} \mathrm{C}$. The glass was refined at $1150^{\circ} \mathrm{C}$ for 3 hours and then annealed at $500^{\circ} \mathrm{C}$ for 1 hour. The composition of the cold HLW glass is listed in Table 1. Radioactive cesium and strontium were replaced by their stable isotopes. Actinides and technetium were substituted, respectively, by neodymium and molybdenum.

2.2. The Preparation of the Glass Samples. The fabricated glass was ground and sieved. The particles ranged from 80 to 120 meshes were selected as the samples. Firstly, the sample 
TABLE 1: The Composition of the simulated HLW (wt\% mass of the oxides).

\begin{tabular}{lc}
\hline Oxide & Content \\
\hline $\mathrm{SiO}_{2}$ & 50.2320 \\
$\mathrm{~B}_{2} \mathrm{O}_{3}$ & 18.4800 \\
$\mathrm{Na}_{2} \mathrm{O}$ & 11.0064 \\
$\mathrm{Li}_{2} \mathrm{O}$ & 1.9320 \\
$\mathrm{Al}_{2} \mathrm{O}_{3}$ & 2.9400 \\
$\mathrm{CaO}$ & 4.5360 \\
$\mathrm{MgO}$ & 0.8400 \\
$\mathrm{SrO}$ & 0.0368 \\
$\mathrm{Y}_{2} \mathrm{O}_{3}$ & 0.0160 \\
$\mathrm{MoO}_{3}$ & 0.1941 \\
$\mathrm{MnO}_{2}$ & 0.0160 \\
$\mathrm{Cs}_{2} \mathrm{O}$ & 0.1152 \\
$\mathrm{BaO}$ & 0.0208 \\
$\mathrm{Nd}_{2} \mathrm{O}_{3}$ & 1.9728 \\
$\mathrm{Fe}_{2} \mathrm{O}_{3}$ & 3.144 \\
$\mathrm{NiO}$ & 0.5728 \\
$\mathrm{~K}_{2} \mathrm{O}_{\mathrm{P}_{2} \mathrm{O}_{5}}$ & 0.0912 \\
$\mathrm{SO}_{3}$ & 0.0688 \\
$\mathrm{TiO}_{2}$ & 0.6448 \\
$\mathrm{Cr}_{2} \mathrm{O}_{3}$ & 0.8400 \\
\hline
\end{tabular}

TABLE 2: The composition of Beishan underground water.

\begin{tabular}{lcccccc}
\hline Elements & $\mathrm{Na}^{+}$ & $\mathrm{K}^{+}$ & $\mathrm{Ca}^{2+}$ & $\mathrm{Mg}^{2+}$ & $\mathrm{Fe}($ total $)$ & $\mathrm{F}^{-}$ \\
\hline $\begin{array}{l}\text { Concentration } \\
(\mathrm{mg} / \mathrm{L})\end{array}$ & 1027 & 16.1 & 206 & 51.2 & 0.25 & 1.89 \\
$\begin{array}{l}\text { Elements } \\
\mathrm{Cl}^{-}\end{array}$ & $\mathrm{Br}^{-}$ & $\mathrm{CO}_{3}{ }^{2-}$ & $\mathrm{NO}_{3}{ }^{-}$ & $\mathrm{SO}_{4}{ }^{2-}$ & $\begin{array}{c}\mathrm{SiO}_{2} \\
\text { (total) }\end{array}$ \\
$\begin{array}{l}\text { Concentration } \\
(\mathrm{mg} / \mathrm{L})\end{array}$ & 1155 & 0.057 & 138 & 30.2 & 1074 & 13.1 \\
\hline
\end{tabular}

powder was ultrasonic washed in deion water for 3 minutes each time for 3 times. Secondly, the sample powder was ultrasonic washed in ethanol for 3 minutes each time for 3 times. Finally, sample powder was heated at $110^{\circ} \mathrm{C}$ for 2 hours.

2.3. The Leaching Procedure. Beishan underground water was ultrafiltered to 10000 Dalton and was used for leaching the glass. The $\mathrm{pH}$ of the Beishan Underground water is 8.01 and the composition is listed in Table 2.

The glass powder and the Beishan underground water were placed in an inner Teflon vessel encased in a stainless steel outer vessel. The glass-surface-area-to-solution-volume ratio is of $6000 \mathrm{~m}^{-1}$ ( $15 \mathrm{~g}$ glass immersed in $40 \mathrm{~mL}$ solution). The operation was conducted in an anoxic glove box with the oxygen content less than $10 \mathrm{ppm}$ to simulate the repository conditions. After sealing, the immersion vessels were transferred to the oven at the temperature of $90^{\circ} \mathrm{C}$ and $150^{\circ} \mathrm{C}$, respectively. Having heated for 24 hours, the vessels were taken out of the oven for further sealing. The immersion periods were designated as the following intervals: 7, 14, 28, 90, 180, 396, 546, and 730 days. At each interval, the vessel was transferred to the anoxic glove box and cooled to the ambient temperature. The solution was filtered to 10000 Dalton, measured for $\mathrm{pH}$, and acidified for solution analysis. The glass powder was heated at $50^{\circ} \mathrm{C}$ to constant weight.

2.4. The Solution Analysis. The solution was measured by ICP-AES Instrument typed VERIN VISTA-MPX for Si, B, $\mathrm{Al}, \mathrm{Fe}, \mathrm{Ca}, \mathrm{Mg}, \mathrm{Na}, \mathrm{Li}, \mathrm{Cs}$, and Mo with the detecting limit of $10^{-9} \mathrm{~g} / \mathrm{mL}$. The element Nd was analyzed by ICP-MS Instrument-typed Perkinelmer DRC-e with the detecting limit of $10^{-12} \mathrm{~g} / \mathrm{mL}$.

2.5. The Analysis of the New Formed Crystals by XRD/EDS. The crystals were determined by XRD typed Dmax $12 \mathrm{~kW}$ using powdered glass samples. The glass samples were scanned continuously stepping $0.2^{\circ} 2 \theta$ using copper X-radiation generated at $40 \mathrm{kV}$ and $100 \mathrm{~mA}$. The main elements in the crystal were determined by the typical energy distribution spectroscopy (EDS).

\section{Results}

3.1. The Leaching of the Main Elements Immobilized. The leaching of the glass modifying elements $\mathrm{Na}$ and Li was displayed in Figure 1 and the leaching curve of $90^{\circ} \mathrm{C}$ and $150^{\circ} \mathrm{C}$ was very different. The $\mathrm{Na}$ and $\mathrm{Li}$ were leached very limited at $90^{\circ} \mathrm{C}$ but were released sharply after a stagnant alteration period of the 180 days at $150^{\circ} \mathrm{C}$. During the rapid release at $150^{\circ} \mathrm{C}$, the leaching behavior of $\mathrm{Na}$ is different from that of Li. The $\mathrm{Na}$ concentration in the aqueous media reached a maximum peak at the 546 immersion days and then was decreased. The $\mathrm{Li}$ concentration reached the maximum at the 546 immersion days and kept stable.

The leaching of glass forming elements of $\mathrm{Si}, \mathrm{B}$, and $\mathrm{Al}$ at $90^{\circ} \mathrm{C}$ and $150^{\circ} \mathrm{C}$ was showed in Figure 2 and the leaching at $90^{\circ} \mathrm{C}$ was very limited. Similar to the Na leaching behavior at $150^{\circ} \mathrm{C}$, the sharp release of $\mathrm{B}$ from glass occurred at the 180 immersion day and the maximum peak was at the $546 \mathrm{im}$ mersion day. The other two glass network forming elements had the different behavior. The Si concentration was increased at the beginning immersion period of 180 days and then it varied with immersion time. The Al concentration was kept constant at the minimum plateau for the beginning immersion period of 180 days and was increased linearly thereafter.

The leaching of Radionuclide Surrogate Elements Nd, $\mathrm{Mo}, \mathrm{Sr}$, and Cs was presented in Figure 3. Sr is very different from the other three elements. The concentration in the immersion media at low temperature is more than that at high temperature and its leaching concentration was decreased with the increase of immersion of time. $\mathrm{Nd}$ was leached more at $150^{\circ} \mathrm{C}$ than at $90^{\circ} \mathrm{C}$. The temperature impacted significantly the leaching of Mo and Cs. At $90^{\circ} \mathrm{C}$, the leaching of $\mathrm{Cs}$ and Mo was very limited. While at $150^{\circ} \mathrm{C}$, the Mo and Cs were released up to $73.6 \%$ and $2.7 \%$ respectively. The large quantity release of Mo was caused by the reprise of alteration.

3.2. The New Formed Phases during the Alteration. New secondary alteration phases were formed for glasses immersed at $150^{\circ} \mathrm{C}$ while no new minerals were found for glasses immersed at $90^{\circ} \mathrm{C}$. There occurred a very thin white crust on 


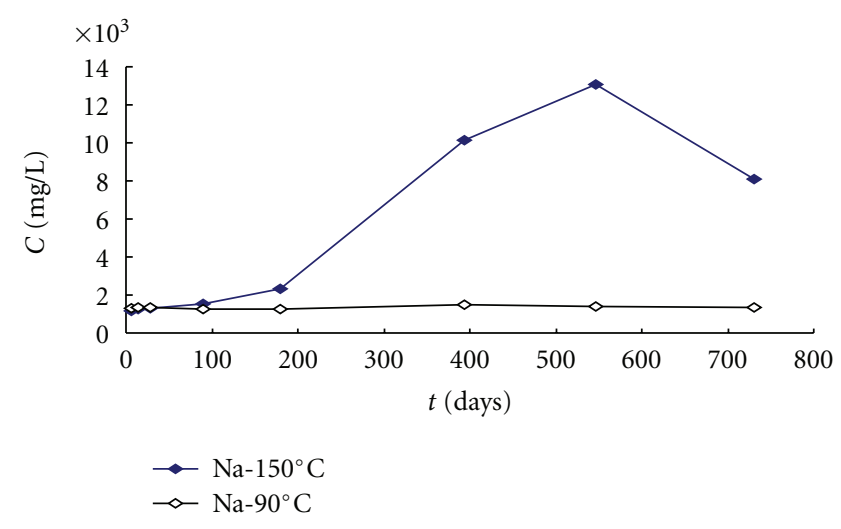

(a)

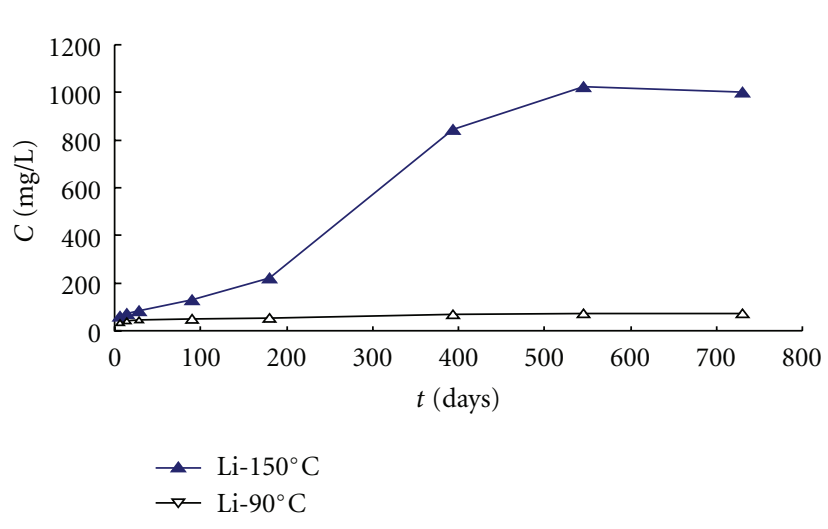

(b)

FIGURE 1: The leaching of the glass modifying elements.

TABLe 3: Mineral distribution of secondary products.

\begin{tabular}{|c|c|c|c|c|c|c|c|c|}
\hline Immersion time & Zeolite P & Mordenite & Nontronite & Dickite & Okonite & Quartz & Saponite & Tincalconite \\
\hline 394 days & $12 \%$ & $28 \%$ & $25 \%$ & & & $35 \%$ & & \\
\hline 546 days & $2 \%$ & & & $6 \%$ & $1 \%$ & & $55 \%$ & $35 \%$ \\
\hline 730 days & & & & & & & & $100 \%$ \\
\hline
\end{tabular}

top of the glass samples immersed for 394 days at $150^{\circ} \mathrm{C}$. With the immersion time increasing, the amounts of new products were increased. Thick white layers were found to be deposited on the inner surfaces of the immersion container and also on top of the glass samples immersed for 546 days. For glass samples immersed for 730 days, large amounts of white powders were precipitated from the immersion solutions just as displayed in Figure 4.

As glass alteration under way, typical minerals occurred at different immersion stages. For glasses Immersed for 394 days, the typical crystal was shaped like long white rods as showed by SEM image in Figure 4 (in the middle of left column). The main elements were analyzed to be $\mathrm{Si}$ and $\mathrm{O}$ as displayed in Figure 4 (at the bottom of the left column), so the main crystal phase could be quartz. For glasses immersed for 546 days, the different crystal phases existed as shown in Figure 4 (in the middle of center column), and they were consisted of elements of $\mathrm{Si}, \mathrm{O}, \mathrm{Na}, \mathrm{Ca}, \mathrm{Cl}$, and $\mathrm{S}$ shown in Figure 4 (at the bottom in the center column). For glasses immersed for 730 days, the typical crystal phases are very clear. The crystal image is cubic shown in middle of right column and the crystal was consisted of $\mathrm{Na}$ and $\mathrm{B}$. Therefore the new white powder should be borax.
The XRD tests have provided definite information of the typical minerals displayed in Figure 5 and Table 3. For glasses immersed for 394 days, the minerals were mainly quartz, mordenite, nontronite, and zeolite P. For glasses immersed for 546 days, the minerals were saponite, tincalconite, dickite, and zeolite P. For glasses immersed for 730 days, the crystal is only tincalconite.

\section{Discussions}

The glass alteration development at $150^{\circ} \mathrm{C}$ has the characteristic of typical consecutive hydrothermal reactions starting from glass dissolution followed by the formation of secondary minerals. As a result, the glass was degraded into silicate minerals and other salts such as tincalconite.

When the glass is contacted with water, water molecules will diffuse through glass-water interface into the glass matrix [9], followed by ion exchange [10] as shown by reaction (1). The hydrogen ion will replace the alkaline metal ions such as sodium and lithium immobilized in glass and alkaline ions will be leached out of the glass. The $\mathrm{pH}$ of immersion solution therefore started to increase: 


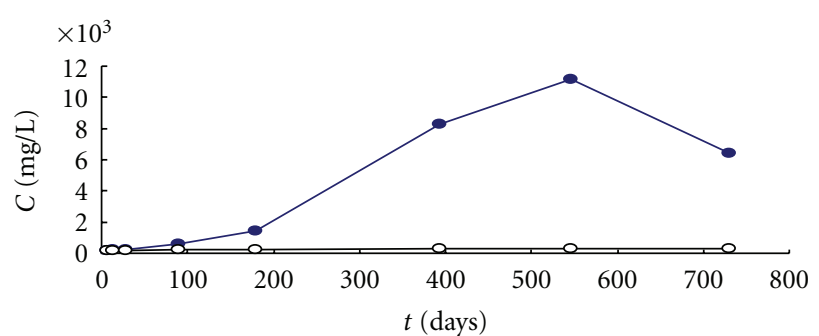

$\longrightarrow \mathrm{B}-150^{\circ} \mathrm{C}$

$\rightarrow$ B- $90^{\circ} \mathrm{C}$

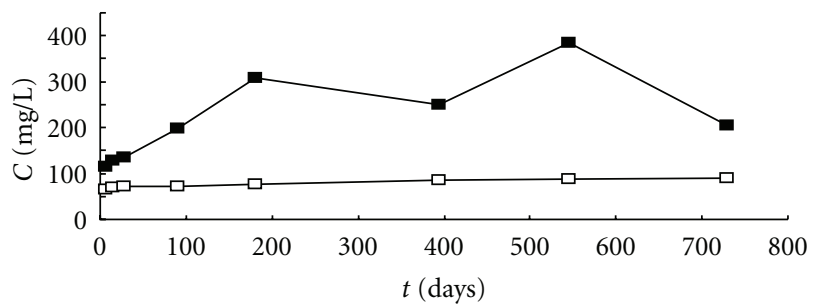

$\rightarrow$ Si- $150^{\circ} \mathrm{C}$

$\rightarrow \mathrm{Si}-90^{\circ} \mathrm{C}$

(b)

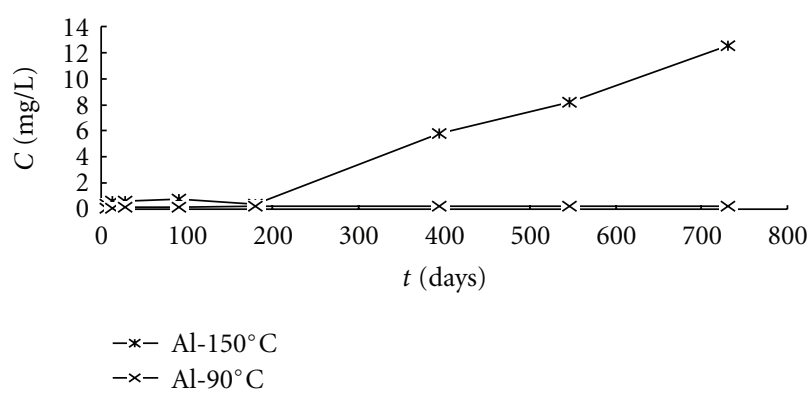

(c)

FIGURE 2: The leaching of the glass network forming elements.

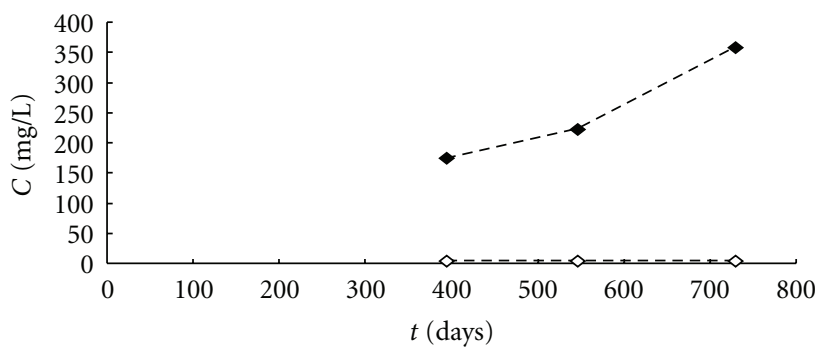

- - Mo- $150^{\circ} \mathrm{C}$

$-\diamond-\mathrm{Mo}-90^{\circ} \mathrm{C}$

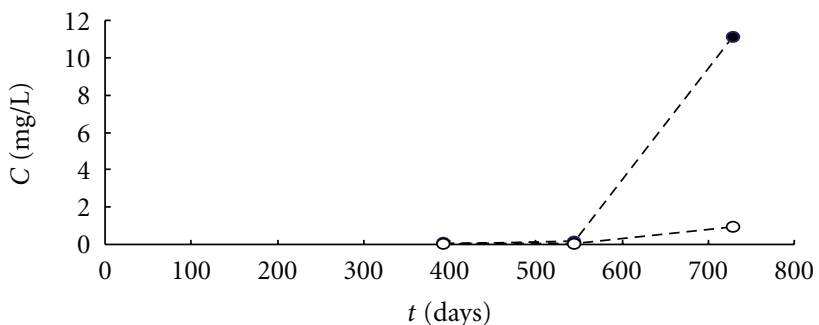

- $\mathrm{Cs}-150^{\circ} \mathrm{C}$

- o- Cs $-90^{\circ} \mathrm{C}$

(b)

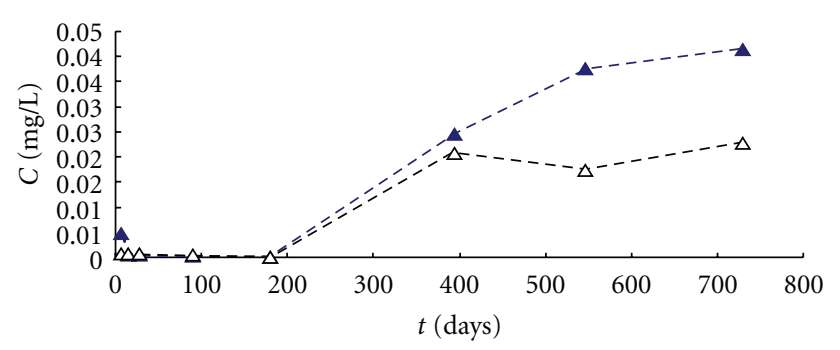

$$
\begin{aligned}
& -\Delta-\mathrm{Nd}-150^{\circ} \mathrm{C} \\
& -\Delta-\mathrm{Nd}-90^{\circ} \mathrm{C}
\end{aligned}
$$

(c)

Figure 3: The leaching of radionuclide surrogate elements. 

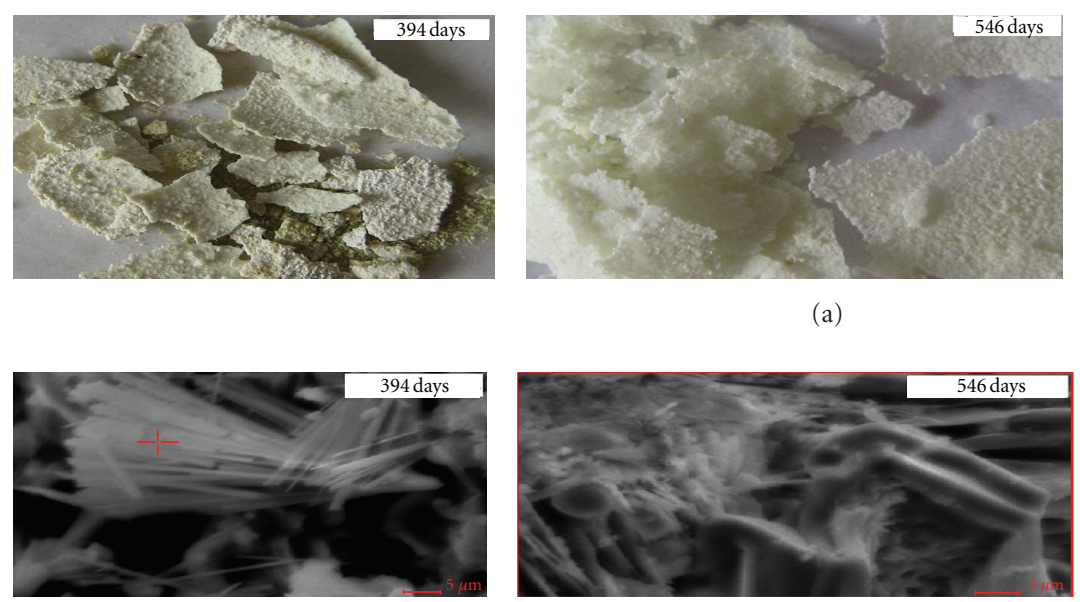

(b)

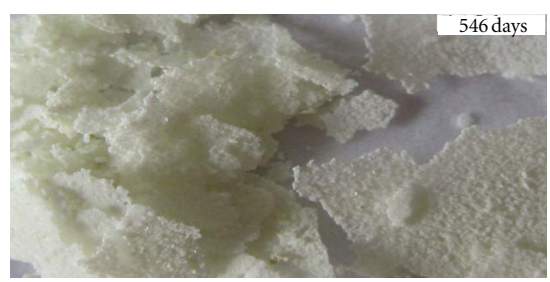

(a)
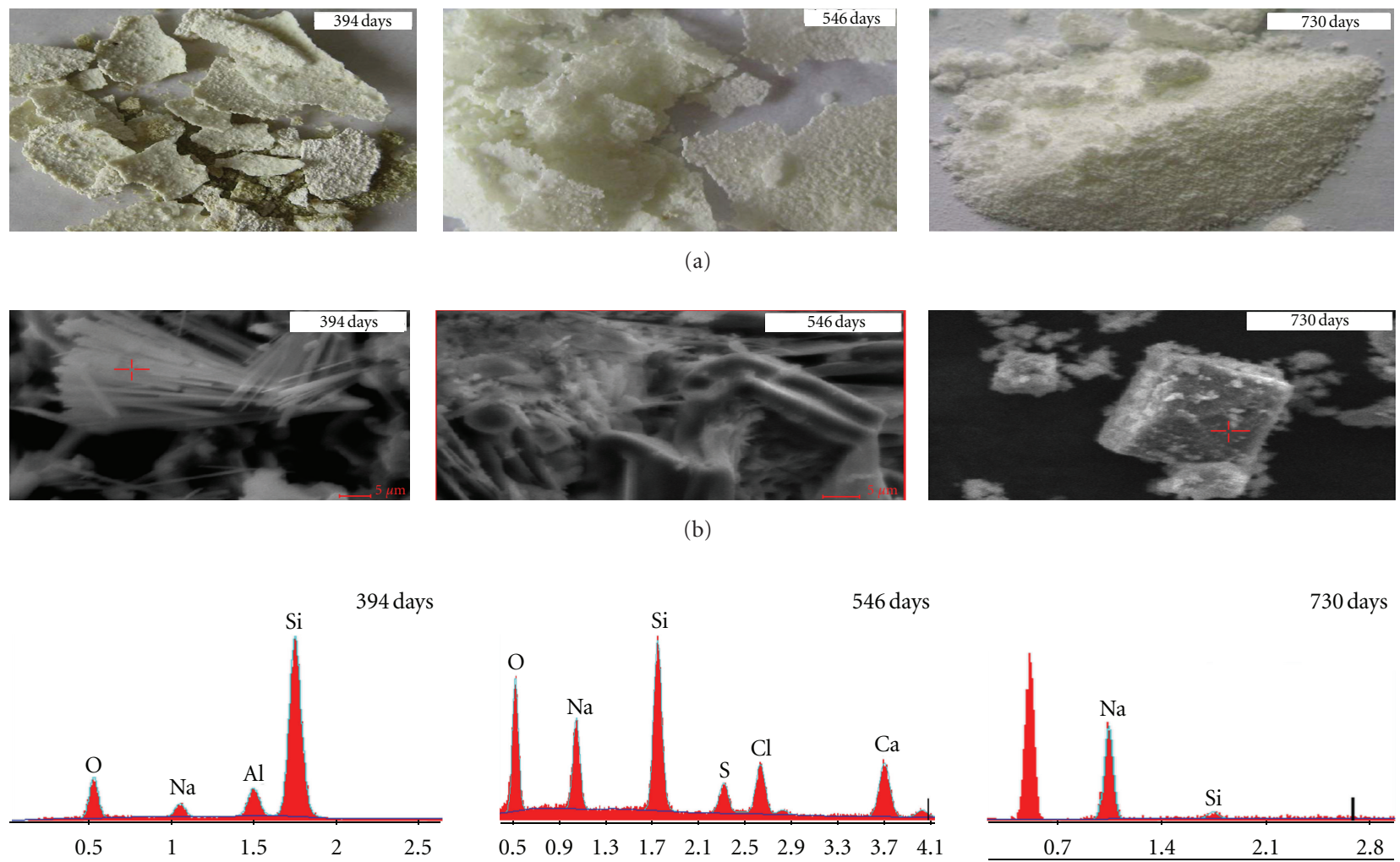

(c)

FIgURE 4: The secondary products (a), their SEM images (b), and their EDS (c).

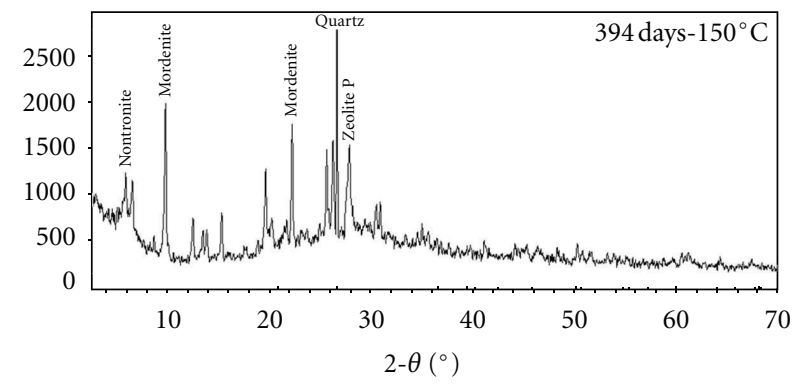

(a)

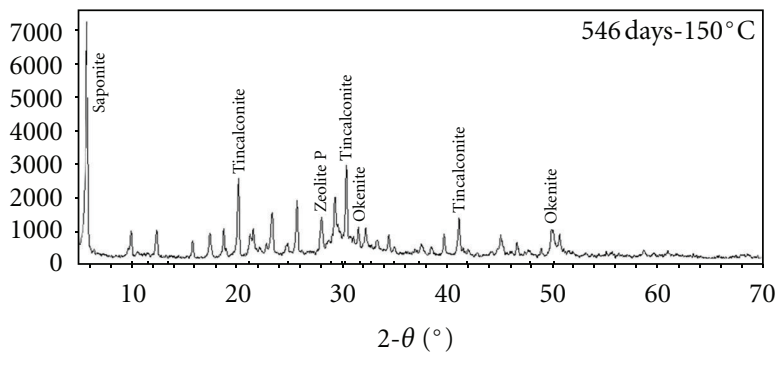

(b)

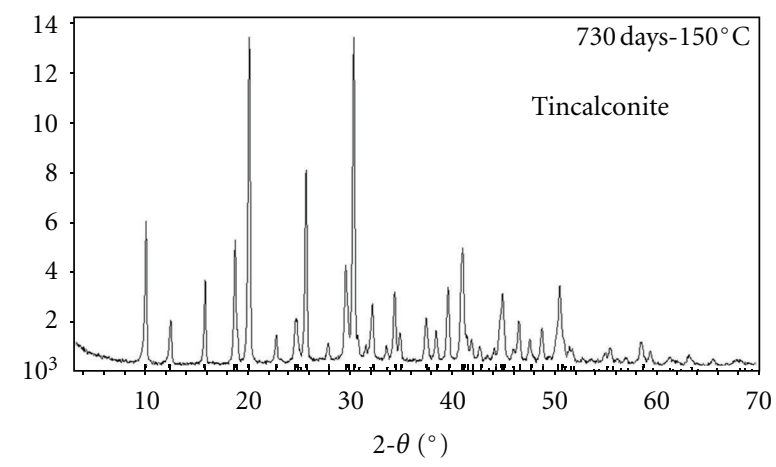

(c)

FIGURE 5: XRD of secondary product for different immersion periods. 
With the release of alkaline metal elements and the increasing of $\mathrm{pH}$ of the immersion solution, the hydrolysis of the network of the surface glass began to occur and leads to the dissolution [11-14] of the glass surface layer as given by reaction $(2)$ :

$$
\begin{aligned}
& {\left[\equiv \mathrm{Si}-\mathrm{O}-\mathrm{Si}(\mathrm{OH})_{3}\right]_{\text {glass }}+\mathrm{OH}^{-} } \\
& \longrightarrow\left[\equiv \mathrm{Si}-\mathrm{O}^{-}\right]_{\text {glass }}+\mathrm{H}_{4} \mathrm{SiO}_{4} .
\end{aligned}
$$

As the hydrolysis-dissolution reactions continued, a gel layer on the glass surface was formed $[15,16]$. In this gel layer, $\mathrm{Na}, \mathrm{Li}$, and $\mathrm{B}$ were all leached into the immersion solution where a portion of silica was retained. With glass dissolution under way, the alkaline metal elements and the boron in the glass matrix would diffuse through the gel layer into the immersion solution, some silica in the gel layer will dissolute into the solution, and some silica in the glass matrix would be transformed into the gel component. As a result, the concentration of silica in the immersion solution will increase and could reach its saturation concentration in certain conditions. Therefore a precipitation reaction of silica would happen in the gel layer and the gel layer would become denser. A balance would be established between glass dissolution and silica precipitation as shown in reaction (3). That is why the glass was very stable when they were immersed in underground water at $90^{\circ} \mathrm{C}$ all the time and at the first stage of immersion at $150^{\circ} \mathrm{C}$ :

$$
\mathrm{H}_{4} \mathrm{SiO}_{4} \text { (aqueous) } \longleftrightarrow \mathrm{SiO}_{2} \text { (gel) }+\mathrm{H}_{2} \mathrm{O} .
$$

But the glass dissolution and precipitation at $150^{\circ} \mathrm{C}$ are very complicated due to the high saturation solubility of silica as well as the formation of secondary products. As the dissolution continued, the silica concentration should be increased to the saturation concentration of the quartz and the saturation concentration of the zeolites such as zeolite $\mathrm{P}$, mordenite, and Nontronite. As a result the new formed products should be precipitated from the solution in the forms of quartz, Zeolite P, mordenite, and nontronite as given by reactions (4) and (5):

$$
\begin{gathered}
\mathrm{H}_{4} \mathrm{SiO}_{4} \text { (aqueous) } \rightarrow \mathrm{SiO}_{2} \text { (quartz) } \\
\mathrm{aMa}^{+}+\mathrm{bMb}^{2+}+\mathrm{cMc}^{3+}+\mathrm{dH}_{4} \mathrm{SiO}_{4} \text { (aqueous) } \rightarrow \text { Zeolite. }
\end{gathered}
$$

Once the zeolite and quartz occurred [17], the consecutive reactions of glass degradation were established as given by reaction (6), and the glass should be transformed into the silicate minerals. As a result, large amounts of immobilized elements such as $\mathrm{Na}, \mathrm{B}, \mathrm{Li}$, and $\mathrm{Al}$ would be released. When the concentration of $\mathrm{Na}$ and $\mathrm{B}$ reached the saturation concentration, they were precipitated as the Tincalconite $\left(\mathrm{Na}_{2} \mathrm{~B}_{4} \mathrm{O}_{7} \cdot 5 \mathrm{H}_{2} \mathrm{O}\right)$ from the immersion solution:

$$
\text { Glass } \longleftrightarrow \text { Silica (aqueous) } \longrightarrow \frac{\text { Quartz }}{\text { Zeolite }} \text {. }
$$

In addition to the glass alteration, the new formed minerals may continue to be transformed from some species to other species.

\section{Conclusions}

The degradation of simulated glass was found to occur in Beishan underground water at $150^{\circ} \mathrm{C}$ in a very high glasssurface-area-to-solution-volume ratio of $6000 \mathrm{~m}^{-1}$ after a stable period of 180 days. The simulated HLW was degraded up to $73.6 \%$ for the immersion period of 730 days resulting in the release of Mo and Cs up to $73.6 \%$ and $2.7 \%$ from the glass, respectively. With the degradation of glass underway, new minerals were found to be zeolite $\mathrm{P}$, mordenite, nontronite, dickite, okonite, quartz, saponite, and tincalconite. The reprise of alteration is mainly caused by the high energy stored in the unrelaxed $\mathrm{Si}-\mathrm{O}$ bond in glass and the energy will be released by forming more stable silicate minerals. The other factors to cause the reprise of alteration could be the high temperature, high glass-surface-area-to-solutionvolume ratio, and high content of salt in the underground water. But the reprise of alteration could be prevented by controlling the temperature of repository below $90^{\circ} \mathrm{C}$.

\section{Acknowledgments}

The authors are grateful to China Atomic Energy Authority (CAEA) for their financial support of this work. They would also like to thank Beijing Research Institute of Uranium Geology for providing the Beishan underground water.

\section{References}

[1] N. Godon et al., "Dossier de reference sur le comportement a long terme des verres nucleaires," Tech. Rep. DTCD/2004/06, 2004.

[2] W. L. Ebert and J. K. Bates, "Comparison of glass reaction at high and low glass surface/solution volume," Nuclear Technology, vol. 104, no. 3, pp. 372-384, 1993.

[3] W. L. Ebert, J. K. Bates, E. C. Buck et al., "The reaction of SRL 202 glass in J-13 and DIW," in Proceedings of the 16th International Symposium in Scientific Basis for Nuclear Waste Management, vol. 294, pp. 137-144, Materials Research Society, 1992.

[4] X. Feng, J. K. Bate, E. C. Buck, C. R. Bradley, and M. Gong, "Long-term comparison of dissolution behavior between fully radioactive and simulated nuclear waste glasses," Nuclear Technology, vol. 104, no. 2, pp. 193-206, 1993.

[5] P. Van Iseghem and B. Grambow, "The long-term corrosion and modeling of the two simulated Belgian reference highlevel waste glasses," in Proceedings of the 11th International Symposium in Scientific Basis for Nuclear Waste Managemen, pp. 631-639, Materials Research Society, 1988.

[6] J. Patyn, P. Van Iseghem, W. Timmermans et al., "The longterm corrosion and modeling of the two simulated Belgian reference high-level waste glasses-Part II," in Proceedings of the 13th International Symposium in Scientific Basis for Nuclear Waste Management, vol. 176, pp. 299-307, Materials Research Society, 1990.

[7] P. Van Iseghem, T. Amaya, Y. Suzuki, and H. Yamamoto, "The role of $\mathrm{Al}_{2} \mathrm{O}_{3}$ in the long-term corrosion stability of nuclear waste glasses," Journal of Nuclear Materials, vol. 190, pp. 269276, 1992.

[8] T. Advocat, P. Jollivet, J. L. Crovisier, and M. Del Nero, "Longterm alteration mechanisms in water for $\mathrm{SON}_{68}$ radioactive 
borosilicate glass," Journal of Nuclear Materials, vol. 298, no. 1-2, pp. 55-62, 2001.

[9] P. Van Iseghem, M. Aertsens, S. Gin et al., in: SCK_CEN, CEA, Subatech, PNNL, SRNL (Eds.), EUR 23097 Ed., p1., 2007.

[10] M. I. Ojovan, A. Pankov, and W. E. Lee, "The ion exchange phase in corrosion of nuclear waste glasses," Journal of Nuclear Materials, vol. 358, no. 1, pp. 57-68, 2006.

[11] H. Scholze, Glass, Nature, Structure, and Properties, Springer, New York, NY, USA, 1991.

[12] B. Grambow and R. Müller, "First-order dissolution rate law and the role of surface layers in glass performance assessment," Journal of Nuclear Materials, vol. 298, no. 1-2, pp. 112-124, 2001.

[13] E. H. Oelkers, "General kinetic description of multioxide silicate mineral and glass dissolution," Geochimica et Cosmochimica Acta, vol. 65, pp. 3703-3719, 2001.

[14] E. H. Oelkers and S. R. Gislason, "The mechanism, rates and consequences of basaltic glass dissolution: I. An experimental study of the dissolution rates of basaltic glass as a function of aqueous $\mathrm{Al}, \mathrm{Si}$ and oxalic acid concentration at $25^{\circ} \mathrm{C}$ and $\mathrm{pH}$ $=3$ and 11," Geochimica et Cosmochimica Acta, vol. 65, no. 21, pp. 3671-3681, 2001.

[15] P. Frugier, S. Gin, Y. Minet et al., " $\mathrm{SON}_{68}$ nuclear glass dissolution kinetics: current state of knowledge and basis of the new GRAAL model," Journal of Nuclear Materials, vol. 380, no. 1-3, pp. 8-21, 2008.

[16] J. L. Crovisier, T. Advocat, and J. L. Dussossoy, "Nature and role of natural alteration gels formed on the surface of ancient volcanic glasses (Natural analogs of waste containment glasses)," Journal of Nuclear Materials, vol. 321, no. 1, pp. 91109, 2003.

[17] D. M. Strachan, "Glass dissolution: testing and modeling for long-term behavior," Journal of Nuclear Materials, vol. 298, no. 1-2, pp. 69-77, 2001. 

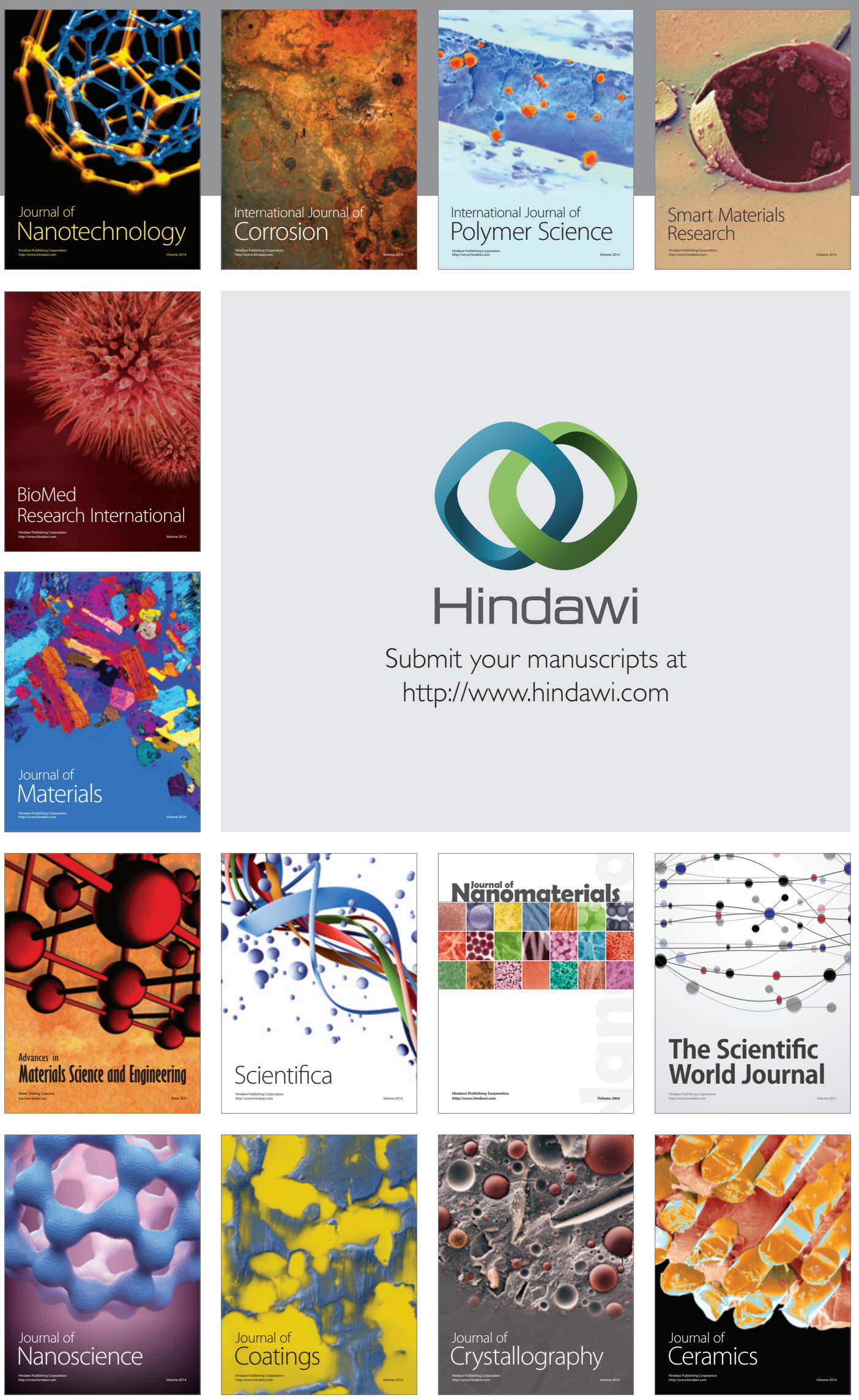

The Scientific World Journal

Submit your manuscripts at

http://www.hindawi.com

\section{World Journal}

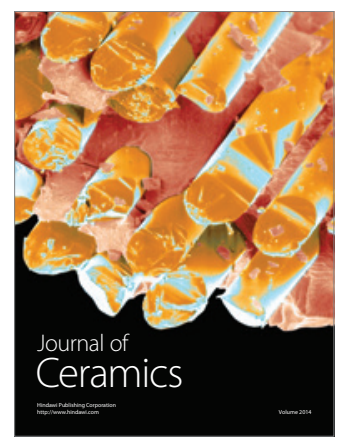

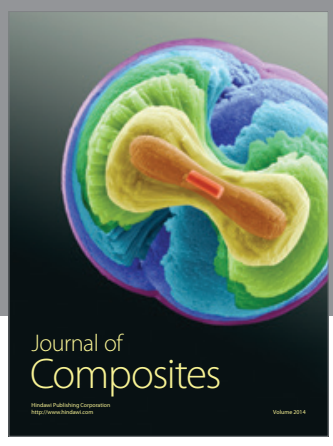
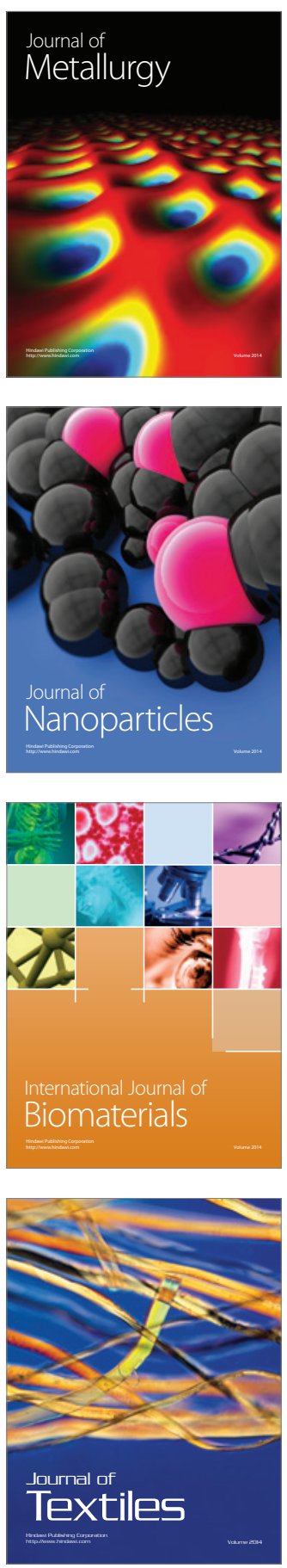